\title{
Use of Simplified Transcriptors for the Analysis of Gene Expression Profiles in Laser-Microdissected Cell Populations
}

\author{
Sandra Lechner, Ulf Müller-Ladner, Elena Neumann, Wolfgang Dietmaier, \\ John Welsh, Jürgen Schölmerich, Josef Rüschoff, and Frank Kullmann \\ Department of Internal Medicine I (SL, UM-L, EN, JS, FK) and Institute of Pathology (WD), University of Regensburg, \\ Regensburg, Germany; Sidney Kimmel Cancer Center (JW), San Diego, California; and Institute of Pathology (JR), \\ Kassel, Germany
}

\begin{abstract}
SUMMARY: Because colorectal epithelia are prone to malignant transformation, it is important to understand their normal regulation and then to identify differences between the normal cells and the transformed cells. We investigated the gene expression pattern along colonic crypts using a novel gene expression analysis strategy. We combined laser-mediated microdissection of distinct areas within colonic crypts and used modified RNA arbitrarily primed PCR to generate probes for cDNA array hybridization. In the basal part of the crypt, proliferation-related and cell cycle-related genes such as the multifunctional transcription factor e2f-1 or the mismatch-related gene $p 58 / H H R 23 B$ were predominantly expressed. In the lumenal part of the crypt, up-regulations of the cysteine protease mch4 and the proto-oncogene c-jun were found. Our findings indicate that e2f1, p58/HHR23B, and mch4 may be involved in key mechanisms leading to malignant transformation in the colonic crypt. Our results also suggest that the technique elucidated here allows identification of gene expression patterns in distinct areas of intestinal tissue samples. (Lab Invest 2001, 81:1233-1242).
\end{abstract}

$B$ ecause colorectal epithelia are prone to malignant transformation it is essential to understand their normal regulation and gene expression pattern. A known gene expression pattern should allow identification of key mechanisms that become apparent and are activated in transformed cells. Intestinal epithelial cells derive from stem cells at the base of the crypt. After migrating along the crypt axis, they detach and are shed after reaching the lumenal surface. In the shedding region, intestinal epithelial cells have apoptotic features. Programmed cell death is thought to play an important role in completing the life cycle of these cells (Potten and Allen, 1977).

However, the molecular mechanisms and signaling pathways that establish and maintain the balance between cellular proliferation, differentiation, and senescence of epithelial cells within the colonic crypt remain largely unknown. Therefore, the identification of a specific gene expression profile in the normal colonic crypt might facilitate a better understanding of the complexity of this microenvironment, and could also have important implications for the study of gastrointestinal carcinogenesis. Because the analysis

Received May 18, 2001

This research was funded by the Deutsche Forschungsgemeinschaft (Ku 1024/6-1 and Mu 1383/3-1) and by Ministry of Education and Research Grant No. 13 N7532 to JR.

Address reprint requests to: Dr. Frank Kullmann, Department of Internal Medicine I, University of Regensburg, D-93042 Regensburg, Germany. E-mail: frank.kullmann@klinik.uni-regensburg.de of differential gene expression of distinct areas such as single colonic crypts was impossible, we developed a novel molecular strategy that allowed the examination of the gene expression pattern along normal colonic crypts.

At present, the study of gene expression in tissue samples is mostly limited by mixed cell populations. The problem of cell heterogeneity has been a significant barrier to the detailed molecular analysis of normal or diseased tissue. Therefore, the preparation of exactly defined, microscopic tissue samples by laser-mediated microdissection (LMM) (Bonner et al, 1997; Emmert-Buck et al, 1996; Simone et al, 1998; Suarez-Quian et al, 1999) provides more specific results.

LMM was developed to provide a rapid and efficient method of capturing and preserving cells of interest from tissue with direct microscopic visualization. After locating the cell(s) of interest under the microscope, a focused, pulsed laser beam is used to encircle the chosen cells, forming a clear-cut gap. The selected area is then transferred via laser pressure catapulting into the cap of a microfuge tube. The procured cells are morphologically intact, can be examined microscopically, and the histologic identity of the captured material can be verified. The immediate immersion of the captured cells into the extraction buffer without manual manipulation further minimizes contamination, which is especially important for PCR-based analysis. Laser treatment does not alter subsequent DNA analysis (Cerroni et al, 1997; Emmert-Buck et al, 1996; 
Tam et al, 1999) or RNA analysis (Emmert-Buck et al, 1996; Fend et al, 1999; Goldsworthy et al, 1999; Nagasawa et al, 2000; Schutze and Lahr, 1998; Sgroi et al, 1999). Additionally, native proteins can be recovered and assayed for function and activity (EmmertBuck et al, 1996) or for proteomic analysis (EmmertBuck et al, 2000).

Cell-specific gene expression patterns of purified cell populations can facilitate the understanding of the molecular basis of cellular events such as proliferation or apoptosis. However, until now, all known screening methods of differential gene expression such as serial analysis of gene expression (Velculescu et al, 1995), subtractive screening (Davis et al, 1987; Diatchenko et al, 1996; Duguid et al, 1988), or cDNA expression arrays (DeRisi et al, 1996; Schena et al, 1995) were limited by the requirement of high amounts (up to 5 $\mu \mathrm{g}$ ) of intact, DNA-free mRNA. Trenkle et al (1998) showed that differential screening of arrays can be considerably improved by systematically increasing the contribution of rare transcripts to the probe. One approach to generate probes with an increased representation of rare mRNAs is to amplify the messages via RNA arbitrarily primed PCR (RAP-PCR). RAP-PCR samples a reproducible subset of the mRNA based on the best match with the arbitrary primers used (Welsh and McClelland, 1990).

In this report, a novel gene expression analysis strategy is demonstrated using the differential display approach of RAP-PCR fingerprinting to generate differential screening probes for cDNA expression arrays. This novel strategy to identify gene expression profiles from very small, histologically defined tissue samples prepared by LMM was developed to study the gene expression pattern of normal colonic crypts. Using this novel approach, we were able to investigate the gene expression pattern of the basal part of colonic crypts versus the lumenal part.

\section{Results}

\section{Efficiency of Different Tissue Fixation Methods}

Complete dehydration of the tissue is necessary for effective LMM transfer. Optimal fixation must provide acceptable morphology, allow adequate laser capture of selected cells, and preserve the integrity of the mRNA. Cross-linking fixatives such as formalin are less suitable for RNA-based applications than precipitative fixatives such as ethanol and acetone (Goldsworthy et al, 1999). To test the efficiency of different tissue fixation methods, we compared the following precipitative dehydration methods for the cryosections: acetone, $70 \%$ ethanol, $100 \%$ ethanol, and ethanol/acetic acid (19:1). All experiments were performed at room temperature and at $-20^{\circ} \mathrm{C}$ for 5 to 10 minutes or 60 minutes.

Optimal fixation (stability and yield of RNA) for the frozen sections was achieved with the ethanol/acetic acid mixture (19:1) at $-20^{\circ} \mathrm{C}$ for approximately 5 to 10 minutes. The quality of the RNA was controlled by RT-PCR, using primers for housekeeping genes (glyceraldehyde-3-phosphate-dehydrogenase, beta2microglobulin, $\beta$-actin; Clontech, Palo Alto, California) (data not shown).

\section{RNA Fingerprinting}

Standard RNA concentrations used for fingerprinting are 100 to $500 \mathrm{ng}$ per reaction. Because LMM material does not provide this amount of RNA, we analyzed samples of $10^{1}, 10^{2}, 10^{3}, 10^{4}, 10^{5}$, and $10^{6} \mathrm{HT}-29$ cells (colon cancer cell line; Deutsche Sammlung für Mikroorganismen und Zellkulturen $\mathrm{GmbH}$, Braunschweig, Germany) by standard RAP-PCR to test the stability and reproducibility of the fingerprint. To be suitable for either gel- or array-based analysis, RAP-PCR fingerprints are required to be identical in parallel reactions with a sample of the same RNA stock solution. Only $10^{5}$ and $10^{6}$ cells were sufficient to perform standardized RAP-PCR. The problem of the low quantity of RNA was solved by using a nested PCR strategy to synthesize the second strand (see "Materials and Methods"). With the introduction of this amplification step, high quality RAP-PCR fingerprints were achievable from lower RNA quantities, derived from at least 20 cells of the HT-29 cell line per reaction (data not shown). Primer combinations using three different primers for reverse transcription and one nested primer set for RAP-PCR were examined. The optimal primer combination was OPN23/OPN21 and OPN21 nested.

Using nested RAP-PCR fingerprinting to examine tissue obtained by LMM, approximately 100 cells were required for adequate reproducibility. RNA preparation from colonic tissue is always critical because of the high enzymatic activity in the colon. Our experiments have shown that fresh immediately frozen endoscopic biopsies are optimal for RAP-PCR with low cell quantities. Low quality RAP-PCR fingerprints were usually the consequence of insufficient RNA quality. Because low amounts of genomic DNA can contribute to the fingerprints, intensive DNase treatment (see "Materials and Methods") is important, especially where LMM samples are used. To test for DNA contamination, one reaction was performed without reverse transcriptase.

\section{Hybridization to Arrays}

RAP-PCR amplifications were used as probes for hybridization to arrays. Figure 1 shows a RAP-PCR fingerprint of RNA from LMM samples (approximately $10^{2}$ cells of a colonic crypt), carried out in duplicate. Only reactions that fulfilled the criteria of reproducibility in standard gel electrophoresis were used. All reactions were first analyzed by gel electrophoresis and autoradiography to check the quality of the RAPPCR step (Fig. 1). Because the array method has such high throughput, this extra control step can greatly improve efficiency by reducing the number of false positives caused by poor RAP-PCR stability.

To hybridize cDNA arrays, high activity radioactive probes are necessary. These were prepared during 


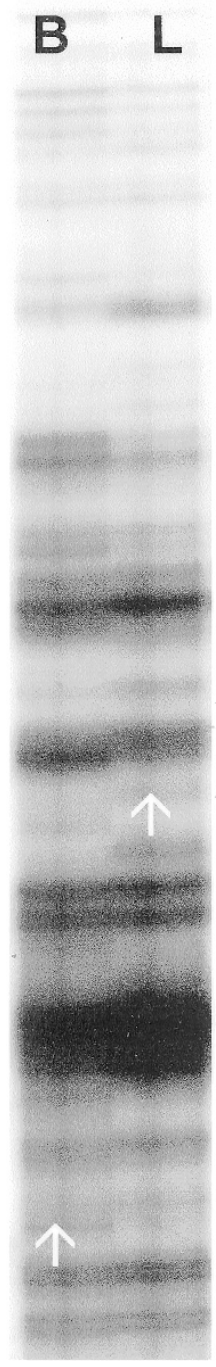

Figure 1.

RNA arbitrarily primed PCR (RAP-PCR) fingerprint of the lumenal part $(L)$ versus the basal part $(B)$ of normal colonic crypts. Thirty colonic crypt parts (half-crypts) were isolated from a cryosection during laser-mediated microdissection (LMM). RAP-PCR was performed with OPN23 and OPN21/OPN21nested primers as described in the "Materials and Methods" section. Each PCR reaction was performed in duplicate. The arrows indicate exemplary differentially amplified fragments that were not further characterized.

RAP-PCR amplification by introducing $\left[\alpha^{-32} \mathrm{P}\right] \mathrm{dATP}$ instead of unlabeled dATP. These radiolabeled probes were then hybridized to Clontech cDNA-arrays.

\section{Microdissection and Differential Gene Expression Analysis of Colonic Crypts}

The combination of LMM and cDNA expression arrays provides a unique opportunity to study gene expression of subpopulations of cells isolated from their native environment (tissue). We examined differential gene expression within normal colonic crypts by comparing the basal (Fig. 2a) versus the lumenal parts of the crypt (Fig. 2b). Colonic crypts were separated by LMM into the basal part of the crypt and into the lumenal part of the crypt (Fig. 2).

One-third of each preamplification reaction (first step of nested RAP-PCR) was checked after nested
RAP-PCR for stability by gel electrophoresis (for experimental design, see Fig. 3). Figure 1 shows RAPPCR fingerprints from the basal part of the crypt versus the lumenal part. Exemplary differentially displayed RAP-PCR products are indicated. The remaining two-thirds of each population were used for the generation of radiolabeled probes for cDNA expression arrays (Fig. 3). This fraction was divided into two independent probe-generating reactions. The arrays with the cell cycle-related and the apoptosis-related genes are shown in Figure 4. Each of the hybridization experiments was performed in duplicate (from LMM to array hybridization). Additional genes with similar levels of difference to the genes indicated as differentially expressed were observed, but the differential expression of these genes was not reproducible in the duplicate hybridization experiments.

Comparative gene expression analysis of intestinal epithelial cells of the basal versus lumenal part of the crypt is shown in Table 1. In total, we found four genes that were differentially expressed in the basal and lumenal parts of normal colonic crypts using RNA fingerprinting in combination with cDNA hybridization after LMM. Furthermore, five genes were detected in all experiments and were expressed constantly in the lumenal and basal parts of the normal colonic crypt.

In general, approximately $1 \%$ of the analyzed cell cycle genes and approximately $1.5 \%$ of the apoptosis-related genes were found to be regulated differentially in the basal part of the colonic crypts as compared with the lumenal part of the colonic crypts using one primer combination for RAP-PCR. As shown in Figure 4, distinct and easily identifiable, differentially expressed genes were observed. The evaluation was performed using the Atlaslmage 2.0 software (Clontech), designed for the Atlas cDNA Expression Array. In total, of the 205 apoptosis and 111 cell cycle gene segments spotted onto the Atlas human cDNA expression array membranes, only a small number of expressed genes could be detected. Most of the genes did not show any hybridization signal. The low number of hybridization events may be due to the complexity of the RAP-PCR probe and to the low amount of RNA used.

\section{Validation of Array Data with RT-PCR and Immunohistochemistry}

The genes that indicated differential expression in both independent experiments of each RNA were further investigated. RT-PCR with gene-specific primers was used to confirm the differential expression. Figure 5 demonstrates that the differential expressions of c-jun (a), mch4 (b), p58/HHR23B (c), and e2f1 (d), determined by array hybridization, are similar to those found by RT-PCR. Mch4 and c-jun were dominantly expressed in the lumenal fraction, whereas p58/ $H H R 23 B$ and e2f1 were expressed in the basal fraction of the colonic crypt, confirming the reliability of our array expression profile data.

We also performed immunohistochemical analysis of c-Jun and Mch4 proteins using tissue sections 

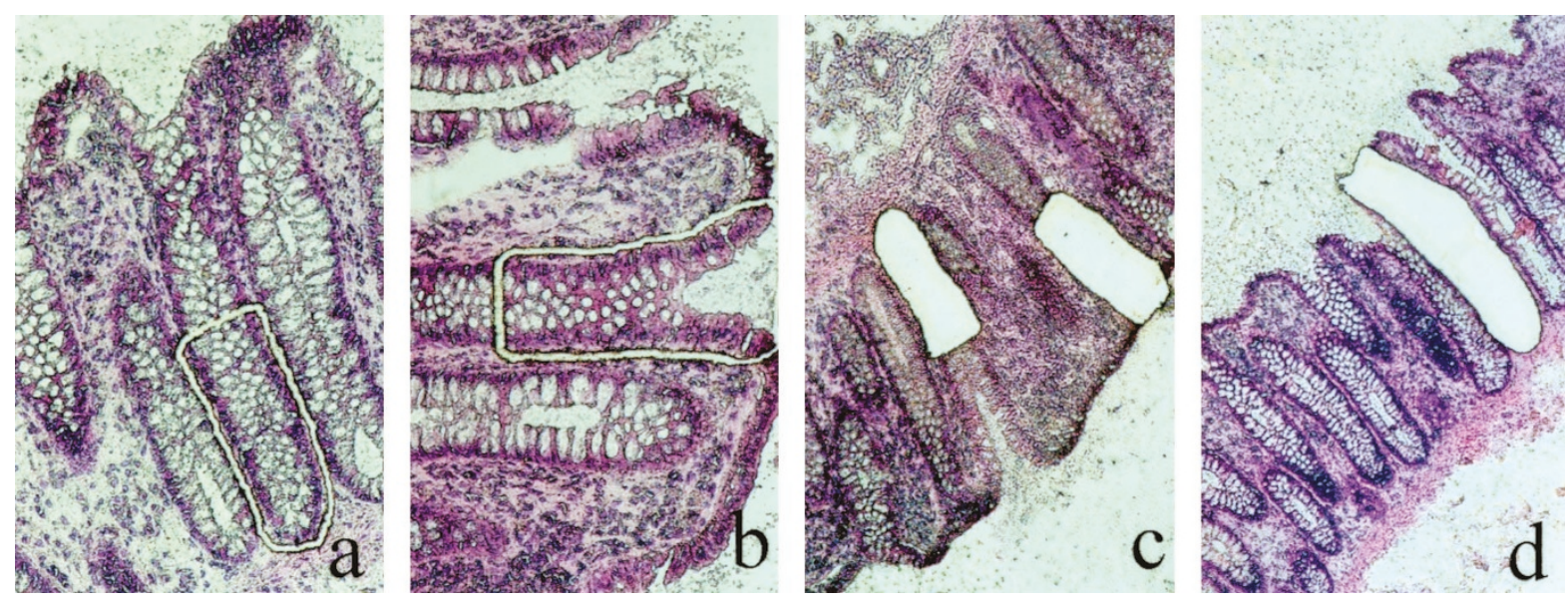

Figure 2.

Demonstration of LMM from sections stained with hematoxylin and eosin of normal colonic crypts (a, b: original magnification, $\times 200$; c, d: original magnification, $\times 100$ ). The cutout of the basal part (a) and of the lumenal part (b) of a colonic crypt is performed using a focused laser beam. The material of interest is transferred into the cap of a reaction tube via laser-pressure catapulting. Panels $\mathrm{c}$ and $\mathrm{d}$ show the final state after laser-pressure catapulting.

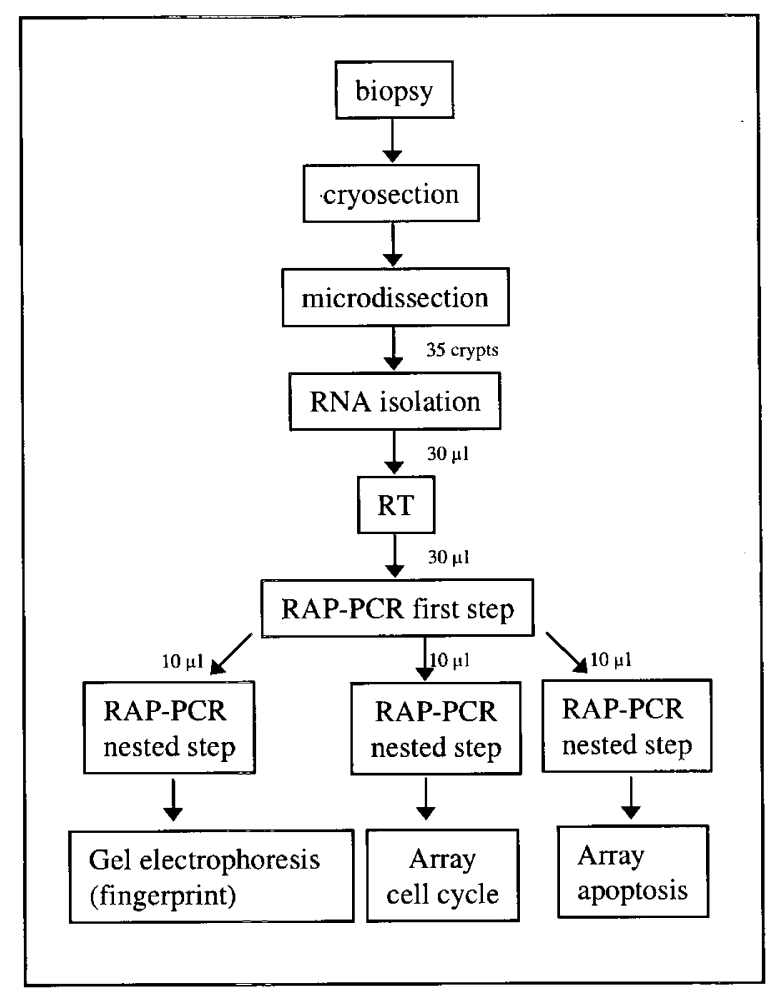

Figure 3.

Experimental design.

adjacent to those used for LMM. Similar to the differential expression pattern observed with the cDNA array and the RT-PCR, the cells in the lumenal area of the crypt showed strong immunoreactivity for c-Jun (Fig. 6, a and b) and for Mch4 (Fig. 6c), whereas the cells of the basal part of the colonic crypt showed less or no immunoreactivity for these proteins. These results further support the reliability of our array data and demonstrate the specific location of the c-Jun and Mch4 expression.

\section{Discussion}

The development of the novel molecular approach to examine differences of gene expression patterns in distinct regions of tissue sections facilitated the analysis of differential gene expression patterns along the axis of the normal colonic crypt. The physiologic regeneration of the colonic epithelium entails proliferation at the crypt base and cell loss by shedding or cell death at the lumenal surface (Potten et al, 1997). The results of this study allow the elucidation of the complex molecular mechanisms within a normal colonic crypt underlying the processes of proliferation, differentiation, or senescence.

At the base of the crypt, the cell cycle-related gene e2f1, a multifunctional transcription factor that binds to the retinoblastoma tumor suppressor (Helin et al, 1992), and the mismatch repair-related gene $p 58 / H H R 23 B$ that codes for the XP-C repaircomplementing protein (Masutani et al, 1994) were dominantly expressed. Both genes are likely to contribute to the proliferative phenotype of intestinal epithelial cells at the base of the crypt. The expression of other marker genes for proliferating cells, such as ki-61, has been demonstrated at the basal and the middle part of the colonic crypt (Johnston et al, 1989).

In the lumenal part of the crypt, intensive expression of $m c h 4$, encoding an apoptotic cysteine protease that is a precursor of caspase-10, which is designated as the executor of the death program (FernandesAlnemri et al, 1996; $\mathrm{Ng}$ et al, 1999), and intensive expression of the nuclear proto-oncogene c-jun, which also induces apoptosis (Leppä et al, 1998; Pandey and Wang, 1995), were observed. The localization of mch4 and c-jun expression to the lumenal zone of the crypt illustrates the high rate of apoptosis of intestinal epithelial cells in this area. Other proapoptotic genes, such as bax or bak, are also expressed preferentially at the lumenal part of the crypt (Potten et al, 1997). The expression of these genes 
Cell Cycle

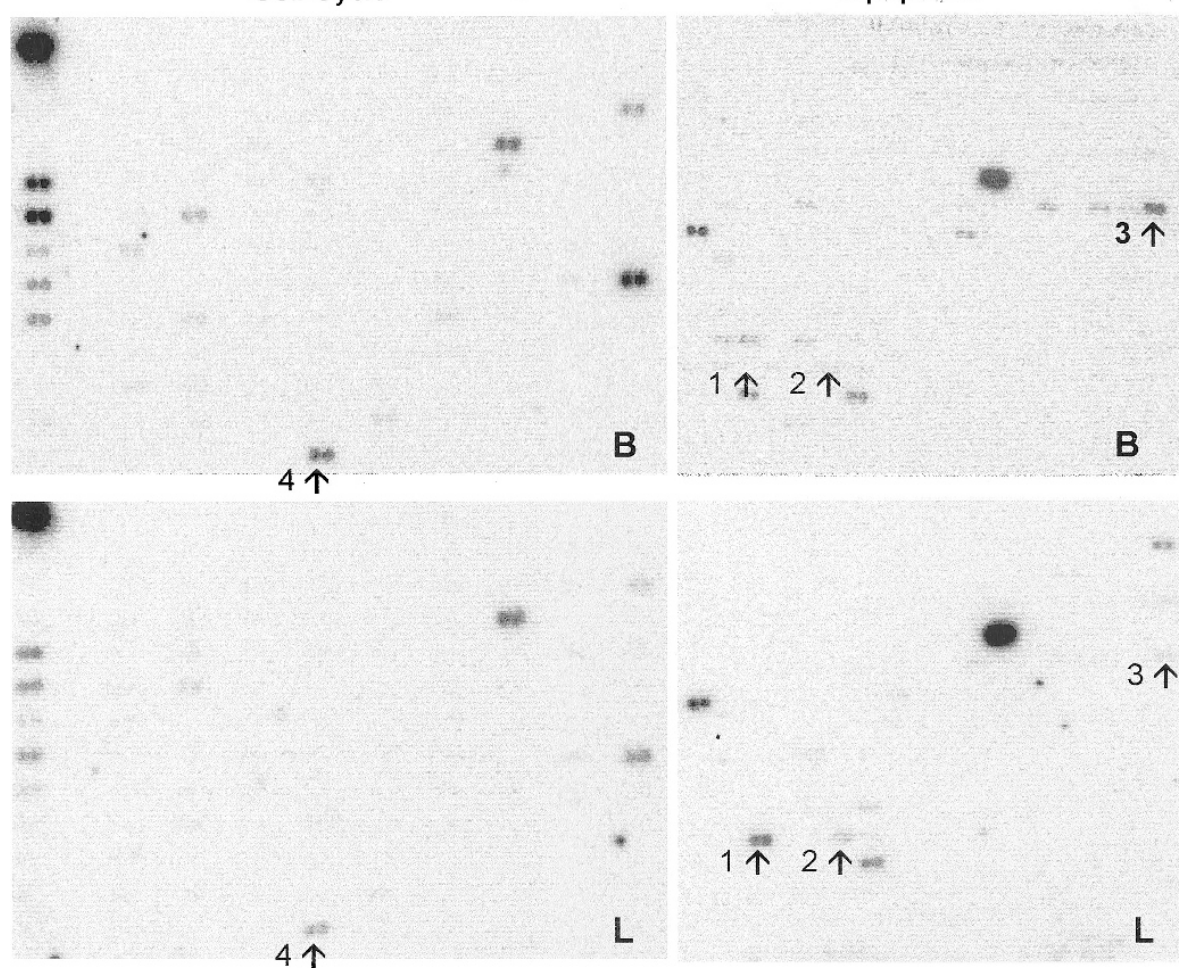

\section{Figure 4.}

Expression patterns of genes in the basal $(B)$ versus the lumenal $(L)$ parts of colonic crypts after LMM. Differential hybridization of two identical Atlas human cDNA expression arrays was performed using RAP-PCR for production of hybridization probes. Double spots represent the expressed genes. Left column (Cell Cycle): section of the expression array membrane with cell cycle-related genes hybridized with cDNA from the basal $(B)$ and the lumenal $(L)$ parts of colonic crypts. Nine positive control housekeeping genes are shown in the left column, followed by four negative controls. Right column (Apoptosis): section of the expression array membrane with apoptosis-related genes hybridized with cDNA from the basal $(B)$ and the lumenal $(L)$ parts of colonic crypts. The arrows indicate the following differentially expressed genes: $1 \uparrow, c-j u n ; 2 \uparrow, m c h 4 ; 3 \uparrow, p 58 / H H R 23 B$; and $4 \uparrow, e 2 f 1$.

indicates early molecular events of apoptosis at the lumenal surface of normal colonic crypts that are essential for the turnover of epithelial cells. Tissue homeostasis depends on both cell death (lumenal surface) and cell proliferation (crypt base).

Our findings indicate that e2f1, p58/HHR23B, mch4, and $c$-jun are involved in the normal physiologic reg- ulation processes of normal colonic crypts to maintain the balance between proliferation and apoptosis. However, p58/HHR23B and mch4 might be interesting candidate genes for key mechanisms leading to malignant transformation in the colonic crypt.

The combined use of LMM and cDNA expression arrays provides a unique opportunity to study gene

Table 1. Listing of Genes Identified to Be Differentially Regulated in the Basal Versus the Lumenal Parts of Normal Colonic Crypts Using LMM, RAP-PCR for Probe Construction and cDNA Expression Array ${ }^{a}$

Expression level (two independent experiments)

\begin{tabular}{|c|c|c|}
\hline Gene & Basal & Lumenal \\
\hline \multirow[t]{2}{*}{$1 \uparrow \mathrm{c}$-jun proto-oncogene (J04111) } & 2 & 42 \\
\hline & 1 & 38 \\
\hline \multirow[t]{2}{*}{$2 \uparrow$ Apoptotic protease MCH4; CASP10 (U60519) } & 4 & 9 \\
\hline & 7 & 15 \\
\hline \multirow[t]{2}{*}{$\begin{array}{c}3 \uparrow \text { Xeroderma pigmentosum group C repair complementing protein } \\
\text { p58/HHR23B (D21090) }\end{array}$} & 59 & 4 \\
\hline & 14 & 7 \\
\hline \multirow[t]{2}{*}{$4 \uparrow$ PRB-binding protein E2F1; RBBP3; RBAP1; PBR3 (M96577) } & 14 & 4 \\
\hline & 21 & 4 \\
\hline
\end{tabular}

LMM, laser-mediated microdissection; RAP-PCR, RNA arbitrarily primed PCR; CASP10, caspase-10 precursor; RBBP3, retinoblastoma-binding protein 3; RBAP1, retinoblastoma-associated protein 1.

${ }^{a}$ Numbers represent relative expression levels, generated using the AtlasImage 2.0 Software (Clontech). $1 \uparrow, 2 \uparrow, 3 \uparrow$, and $4 \uparrow$ correspond to the indications in Figure 4. 


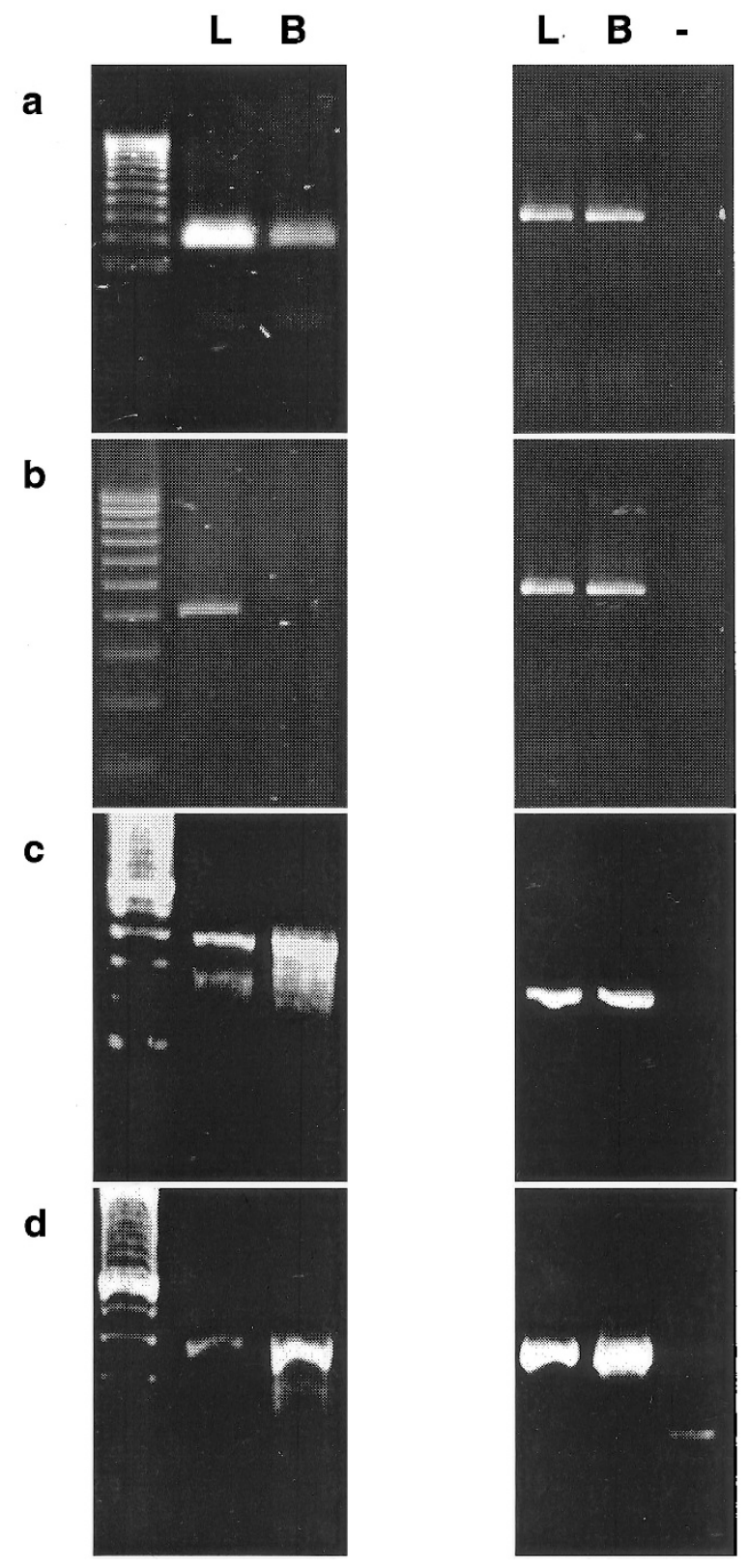

Figure 5.

RT-PCR of LMM colonic crypts using gene-specific primers for $c-j u n(a), m c h 4$ (b), p58/HHR23B (c), e2f1 (d), and $\beta$-actin (control, right column) resolved on a $2 \%$ agarose gel (stained with ethidium bromide). $L$, lumenal part of colonic crypts; $B$, basal part of colonic crypts; -, negative control; marker, $100 \mathrm{bp}$ ladder.

expression of subpopulations of cells in their native tissue environment. Using LMM, the genetic analysis of pure and very small cell populations is possible and the limitations associated with in vivo and in vitro studies can be minimized. Because the number of cells obtained by microdissection is usually very low and the corresponding amount of RNA does not usually allow array hybridization, we added RAP-PCR as an amplification step to generate probes sufficient for array hybridization. Trenkle et al (1998) showed that differential screening of arrays can be considerably improved by systematically increasing the contribution of rare transcripts to the probe.
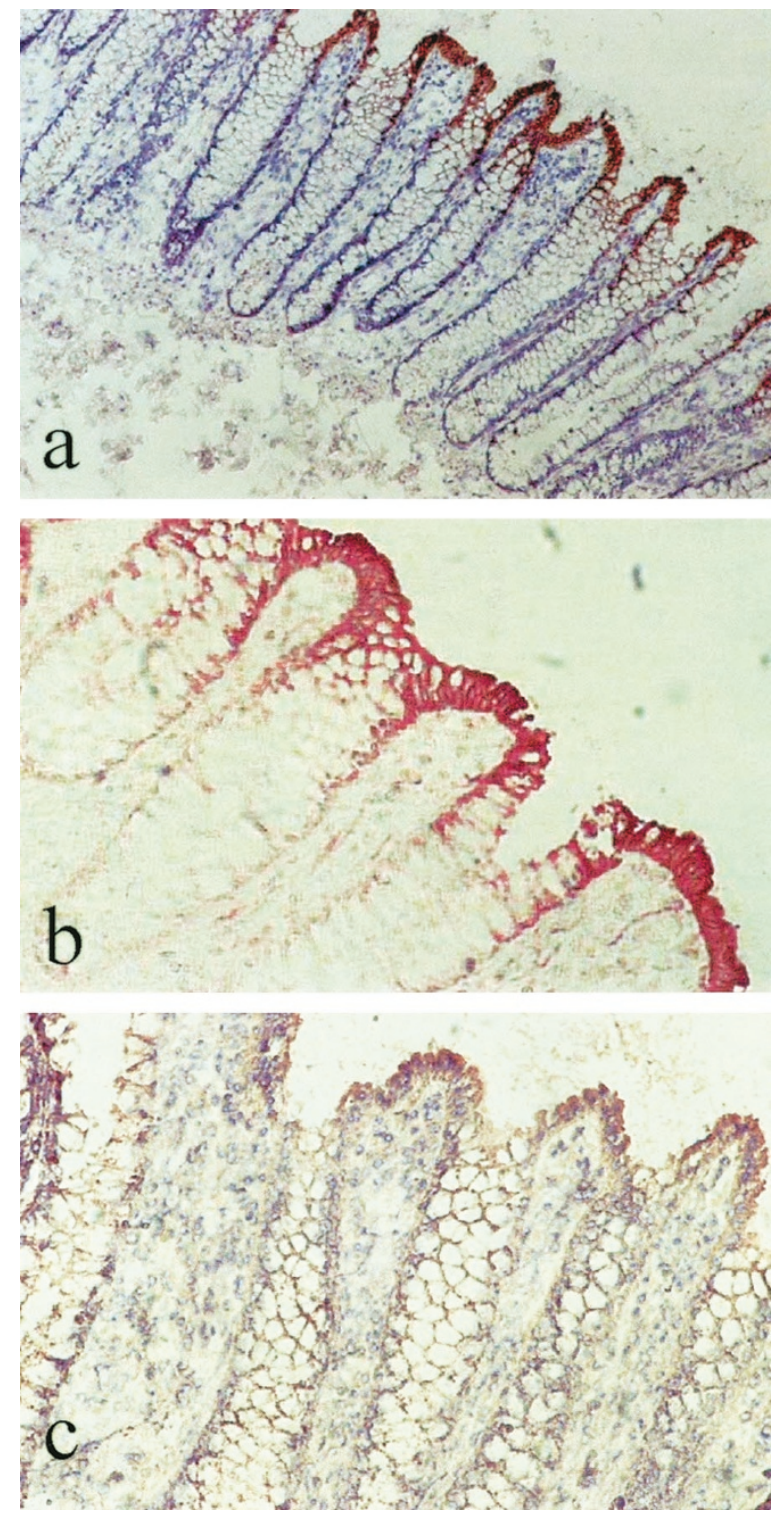

Figure 6.

Immunohistochemistry of colonic crypts using monoclonal antibodies against c-Jun ( $\mathrm{a}$ and b) or Mch4 (c). Note the strong expression of c-Jun and Mch4 in the lumenal parts of normal colonic crypts in comparison with the basal parts. Tissue sections adjacent to those used for LMM (RAP-PCR, CDNA expression array, RT-PCR) were used. Panels a (with additional hematoxylin staining; original magnification, $\times 100$ ) and $\mathrm{b}$ (without additional hematoxylin staining; original magnification, $\times 200)$ show c-Jun-immunoreactive cells, red-brown colored. Panel c (with additional hematoxylin staining; original magnification, $\times 200$ ) demonstrates Mch4 expression.

In general, the technique of differential cDNA array hybridization is useful when two biologic conditions are compared (Usui et al, 1996); this technique was previously used in cancer research to compare the expression pattern of genes in normal versus tumor tissues (DeRisi et al, 1996; Heller et al, 1997; Oh et al, 1999). Arrays containing cDNA clones can be used to examine hundreds of genes in a single hybridization procedure (DeRisi et al, 1996; Sehgal et al, 1998; Trenkle et al, 1998). Furthermore, it was demonstrated that the cDNA array method allows evaluation of alterations in gene expression with a relatively high 
accuracy (Backert et al, 1999). However, in contrast with other screening methods, less abundant mRNAs are likely to not be identified during CDNA array hybridization because they vanish within the background of the hybridization signals. Mch4 and c-Jun mRNA and protein are dominantly expressed in the lumenal fraction of the colonic crypt as shown by RT-PCR and immunohistochemistry, confirming the reliability of our combination method. The correlations observed between the CDNA array and RT-PCR analysis data are consistent with that observed by others (lyer et al, 1999; Luo et al, 1999; Sgroi et al, 1999). The low number of hybridization events seen in our experiments may be caused by the small amount of RNA used. At present, there are no data on differential gene expression within the colonic crypt. Consequently, we do not know how many genes are involved in physiologic regulation of a crypt. Additionally, the use of nested RAP-PCR for generating CDNA array probes may result in a normalization of mRNA abundance and a reduced number of hybridization signals. When an expanded screening of gene expression is desired, further primer combinations would supply more hybridization events. Nevertheless, no array hybridization would be possible using these low amounts of RNA after LMM without amplification.

Our study reveals that along with original RNA fingerprinting for differential display (McClelland et al, 1995; Welsh et al, 1992), RAP-PCR in combination with cDNA expression array is a suitable method to identify gene expression profiles in very small and exactly defined tissue compartments obtained by LMM. Furthermore, our findings indicate that p58/ HHR23B and mch4 are candidate genes for involvement in key mechanisms leading to malignant transformation in the colonic crypt.

\section{Materials and Methods}

\section{Tissue Sections}

Fresh tissue from normal colonic biopsies was placed in embedding medium (Tissue Tek OCT medium, VWR Scientific Products Corporation, San Diego, California) and immediately snapfrozen in $\mathrm{n}$-buthanol cooled by liquid nitrogen. All cryoblocks were stored at $-80^{\circ} \mathrm{C}$ until cut.

Glass slides were membrane mounted (PEN membrane; P.A.L.M., Wolfratshausen, Germany) and poly-Ilysine coated $(0.2 \%$ poly-l-lysine in sterile, DEPC-treated $\mathrm{H}_{2} \mathrm{O}$ ) under RNase-free conditions. Cryosections (5 to 8 $\mu \mathrm{m})$ were cut in a cryostat, dehydrated with ethanol or acetone, and stained with hematoxylin and eosin.

\section{Microdissection}

LMM was performed using a Robot Microbeam laser microscope (P.A.L.M.). The tissue area of interest was positioned and cut out using a focused, pulsed laser beam. Dissected areas were collected in the cap of a microcentrifuge tube via laser pressure catapulting. The object of interest was catapulted off the slide using a high energy, defocused, short-duration laser pulse, an action that is facilitated by coating the slide with the PEN membrane. The cap with the procured tissue was placed immediately on the microfuge tube containing $300 \mu \mathrm{l}$ of RLT lysis buffer of the RNeasy spin column purification kit (Qiagen, Hilden, Germany), and lysed by mixing. In total, we isolated and pooled 30 to 35 basal and lumenal sections of the crypt of the cryosections of one biopsy of normal colonic mucosa for our experiments.

\section{RNA Extraction}

RNA was extracted by silica gel binding using the RNeasy spin column purification kit (Qiagen). To remove the remaining genomic DNA, total RNA was treated with DNase I (Qiagen) at room temperature for 30 minutes. This step was essential because small amounts of DNA can contribute to false results in the RNA fingerprints. Extraction was performed according to the manufacturer's instructions, and RNA was eluted with $30 \mu$ l of RNase-free water. The $30 \mu$ l eluate was applied to the column and centrifuged to increase the yield of RNA.

\section{RNA Fingerprinting}

RAP-PCR was performed as previously described (Jung et al, 1998). Nested RAP-PCR differs from the original RAP-PCR protocol in a modification of the second strand synthesis; the amplification is performed in two steps (McClelland et al, 1993; Ralph et al, 1993).

Reverse transcription for first strand synthesis was performed with total RNA using a 10-mer arbitrary primer. Three different arbitrary primers were used in independent experiments: US6 (5'-GTGGTGACAG3'), US9 (5'-GTGACAGACA-3'), or OPN23 (5'CAGGGGCACC-3'). RNA (30 $\mu$ l) was mixed with $20 \mu \mathrm{l}$ of reverse transcription mixture for a final $50 \mu \mathrm{l} \mathrm{reac-}$ tion containing $50 \mathrm{~mm}$ Tris/ $\mathrm{HCl} \mathrm{pH} \mathrm{8.3,} 75 \mathrm{~mm} \mathrm{KCl,} 3$ $\mathrm{mm} \mathrm{MgCl} 2$, $20 \mathrm{~mm}$ DTT, $0.2 \mathrm{~mm}$ dNTP, $2 \mu \mathrm{M}$ primer, and $100 \mathrm{U}$ of MuLV reverse transcriptase (Promega, Madison, Wisconsin). To exclude DNA contamination, a reverse transcriptase-free control reaction was included in the RAP-PCR experiments. The reaction was carried out at $37^{\circ} \mathrm{C}$ for 60 minutes, after a 5-minute ramp from $25^{\circ} \mathrm{C}$ to $37^{\circ} \mathrm{C}$; inactivation of the reaction was performed at $68^{\circ} \mathrm{C}$ for 15 minutes. The synthesized CDNA was purified by precipitation and resolved in $30 \mu \mathrm{l}$ of nuclease-free water.

PCR for second strand synthesis was performed using a nested PCR strategy. In the first step, a preamplification was achieved by 15 cycles with a 10-mer arbitrary primer (OPN21; 5'-ACCAGGGGCA$\left.3^{\prime}\right)$. The CDNA $(30 \mu l)$ was mixed with $20 \mu \mathrm{l}$ of PCR mixture for final concentrations of $10 \mathrm{~mm}$ Tris/ $\mathrm{HCl} \mathrm{pH}$ 8.3, $10 \mathrm{~mm} \mathrm{KCl}, 4 \mathrm{~mm} \mathrm{MgCl}$, $0.2 \mathrm{~mm}$ dNTPs, $4 \mu \mathrm{m}$ primer, and $2.5 \mathrm{U}$ of AmpliTaq DNA polymerase Stoffel fragment (Perkin Elmer, Norwalk, Connecticut). Cycling conditions were $94^{\circ} \mathrm{C}$ for 30 seconds, $35^{\circ} \mathrm{C}$ for 30 seconds, and $72^{\circ} \mathrm{C}$ for 60 seconds. 
The PCR product was purified by precipitation and resolved in $30 \mu \mathrm{l}$ of nuclease-free water. Ten microliters of the product of the first amplification step was used for the second amplification step with a nested 10-mer arbitrary primer (OPN21 nested; 5'-CCAGGGGCAC-3'). The nested primer (OPN21 nested) had one additional nucleotide at the 3 '-end of the first primer sequence (OPN21). The reaction was carried out in a volume of 20 $\mu l$ containing $10 \mathrm{~mm}$ Tris/ $\mathrm{HCl} \mathrm{pH}$ 8.3, $10 \mathrm{~mm} \mathrm{KCl,} 4 \mathrm{~mm}$ $\mathrm{MgCl}_{2}, 0.2 \mathrm{~mm}$ dNTPs, $4 \mu \mathrm{m}$ primer, $2.5 \mathrm{U}$ of AmpliTaq DNA polymerase Stoffel fragment (Perkin Elmer), and 2 $\mu \mathrm{Ci}$ of $\left[\alpha^{3}{ }^{32} \mathrm{P}\right] \mathrm{dCTP}(3000 \mathrm{Ci} / \mathrm{mmol}, 0.2 \mu \mathrm{l}$, Amersham, Freiburg, Germany). Cycling conditions were 35 cycles of $94^{\circ} \mathrm{C}$ for 30 seconds, $35^{\circ} \mathrm{C}$ for 30 seconds, and $72^{\circ} \mathrm{C}$ for 60 seconds. All reactions were carried out in duplicate to test the reproducibility and stability of the RNA fingerprint.

An aliquot of the PCR reaction was mixed with loading dye, denatured ( $94^{\circ} \mathrm{C}$ for 3 minutes), and loaded onto on a $8 \mathrm{M}$ urea, $5 \%$ polyacrylamide gel, prepared with Tris-borate-EDTA buffer. Electrophoresis was performed at $45^{\circ} \mathrm{C}$ and $100 \mathrm{~W}$ for approximately 90 minutes. The gel was dried under vacuum at $80^{\circ} \mathrm{C}$ and exposed to a BioMax X-Ray film (Kodak, Stuttgart, Germany).

\section{Atlas cDNA Expression Array}

Two Atlas human cDNA expression arrays (Clontech, Palo Alto, California) designed for evaluation of different molecular expression patterns were used: arrays of 205 known apoptosis-related genes; and arrays of 111 known cell cycle-related genes.

Preparation of Hybridization Probe. The hybridization probe was generated by an amplification of the CDNA via nested RAP-PCR. The PCR product of the first amplification step was amplified in a $20-\mu$ l reaction, as described above, using $28 \mu \mathrm{Ci}$ of $\left[\alpha^{-32} \mathrm{P}\right] \mathrm{dATP}$ (3000 Ci/mmol, $2.8 \mu \mathrm{l}$, Amersham) for labeling instead of the $2 \mu \mathrm{Ci}$ of $\left[\alpha^{-}{ }^{32} \mathrm{P}\right] \mathrm{dCTP}(3000 \mathrm{Ci} / \mathrm{mmol}, 0.2 \mu \mathrm{l}$, Amersham) used for RNA fingerprinting. After confirmation that the RAP-PCR was successful (via gel electrophoresis and autoradiography), the PCR reaction was purified from unincorporated ${ }^{32} \mathrm{P}$-labeled nucleotides and small DNA fragments $(<0.1 \mathrm{~kb})$ by column chromatography using Chroma spin-200 DEPC- $\mathrm{H}_{2} \mathrm{O}$ columns from Clontech, per manufacturer's instructions.

Hybridization. The RAP-PCR product was hybridized to the Atlas human cDNA expression array membranes in roller bottles. The filters were prehybridized in $6 \mathrm{ml}$ of prewarmed $\left(68^{\circ} \mathrm{C}\right)$ hybridization solution (ExpressHyb Hybridization Solution, Clontech) containing $100 \mu \mathrm{g} / \mathrm{ml}$ fragmented denatured salmon sperm DNA (Sigma, Deisenhofen, Germany) for approximately 30 minutes. The labeled hybridization probe $(200 \mu \mathrm{l})$ was denatured by adding $20 \mu \mathrm{l}$ of $10 \mathrm{x}$ denaturing solution ( $1 \mathrm{M} \mathrm{NaOH}, 10 \mathrm{~mm}$ EDTA) and incubated at $68^{\circ} \mathrm{C}$ for 20 minutes. Five microliters of sheared human genomic DNA (Clontech) and $225 \mu \mathrm{l}$ (an equal volume) of $2 x$ neutralizing solution (1 $\mathrm{M}$ $\mathrm{NaH}_{2} \mathrm{PO}_{4} \mathrm{pH}$ 7.0) were added. The reaction was incubated for 10 minutes at $68^{\circ} \mathrm{C}$ and immediately added to the hybridization solution and the prehybridized filters. The filters were hybridized overnight with the radiolabeled probe.

Wash. The filters were washed three times in wash solution 1 (2x SSC and 2\% SDS) for 30 minutes at $68^{\circ} \mathrm{C}$ each. Two washing steps were performed with wash solution $2(0.1 \times \mathrm{SSC}$ and $0.5 \% \mathrm{SDS})$ at $68^{\circ} \mathrm{C}$ for 20 minutes and one step for 5 minutes at room temperature in $2 \times$ SSC and the filters were exposed to a Phosphor-Imager-Screen (Molecular Dynamics, Sunnyvale, California) for approximately 5 days.

Data Analysis. Analysis of the scanned PhosphorImager-Screen was performed using the Ambis software (ImageQuant, Molecular Dynamics). Evaluation was performed using the Atlaslmage 2.0 software, developed specifically for analysis of the Atlas cDNA Expression Arrays (Clontech).

\section{Confirmation of Differential Expression Using Gene-Specific RT-PCR}

The first level of confirmation was achieved by performing each experiment in duplicate (from microdissection to array hybridization), in two parallel reactions under the same conditions. Only those hybridization results that indicated differential expression (2-fold or more disregulation) in both reactions were regarded as valid. Because the sequence information of all clones spotted on the filters is known, gene-specific primers for RT-PCR can be designed immediately.

RNAs were reverse transcribed as described above for RAP-PCR. The PCR reaction was performed using the Qiagen supermix (Qiagen) with a gene-specific forward (mch4_f 5'-GACGAAAGTGGAAATGGAGA-3', c-jun_f 5'-ATGAGGAACCGCATCGCTG-3', p58/ HHR23B_f 5'-GCAACTACGACAGCAACAAC-3', or e2f1_f 5'-GCTGGACCACCTGATGAATA-3') and reverse (mch4_r 5'-GAGACTGAATATACCAGCTG-3', c-jun_r 5'TAGCATGAGTTGGCACCCACTG-3', p58/HHR23B_r 5'-TGGCAGCCAAATTCTCATTC-3', or e2f1_r 5'GATCTGTGGTGAGGGATGAG-3') primer. The following PCR conditions were used: 40 cycles of $94^{\circ} \mathrm{C}$ for 30 seconds; $53^{\circ} \mathrm{C}$ (p58/HHR23B), $55^{\circ} \mathrm{C}$ (mch4 and e2f1), $58^{\circ} \mathrm{C}$ (c-jun) for 30 seconds; and $72^{\circ} \mathrm{C}$ for 60 seconds. As a control, the housekeeping gene $\beta$-actin was amplified using primers from Clontech.

\section{Confirmation of Differential Expression Using Immunohistochemistry}

Immunohistochemistry was performed with monoclonal antibodies against p-c-Jun (Santa Cruz Biotechnology, Santa Cruz, California) or polyclonal antibodies against the caspase-10 precursor, Mch4 (Santa Cruz Biotechnology) using the AEC (3-amino-9ethylcarbazole) substrate kit for peroxidase (Vector Laboratories, Burlingame, California). Snap frozen sections were cut (4 to $6 \mu \mathrm{m}$ ), fixed for 5 minutes in acetone, and covered with a $4 \%$ non-fat dry milk and $2 \%$ normal goat serum buffer for 30 minutes at room temperature to block nonspecific binding. After rinsing 
in Tris- $\mathrm{NaCl} \mathrm{pH} \mathrm{7.6,} \mathrm{the} \mathrm{slides} \mathrm{were} \mathrm{incubated} \mathrm{for} 45$ minutes at room temperature with the primary antibodies diluted 1:50 to $1: 200$ in Tris- $\mathrm{NaCl}$ containing $2 \%$ non-fat dry milk. The slides were rinsed in Tris$\mathrm{NaCl}$ and incubated for 30 minutes at room temperature with secondary biotinylated anti-mouse and antirabbit IgG antibodies, respectively (Pharmingen, San Diego, California), in a 1:400 dilution in Tris- $\mathrm{NaCl}$ containing $2 \%$ non-fat dry milk. Incubation with the AEC substrate was performed for 30 minutes at room temperature. The color development (varying from 10 to 30 minutes) was stopped after microscopic examination by washing with water. The slides were immediately mounted (Gel Mount; Biomeda, Foster City, California) after staining with hematoxylin.

\section{Acknowledgements}

The authors thank Christopher Benzing, Georg Gebhart, and Wibke Ballhorn for excellent technical assistance.

\section{References}

Backert S, Gelos M, Kobalz U, Hanski ML, Bohm C, Mann B, Lovin N, Gratchev A, Mansmann U, Moyer MP, Riecken EO, and Hanski C (1999). Differential gene expression in colon carcinoma cells and tissues detected with a cDNA array. Int J Cancer 82:868-874.

Bonner RF, Emmert-Buck MR, Cole K, Pohida T, Chuaqui R, Goldstein S, and Liotta LA (1997). Laser capture microdissection: Molecular analysis of tissue. Science 278 : 1481-1483.

Cerroni L, Minkus G, Putz B, Hofler H, and Kerl H (1997). Laser beam microdissection in the diagnosis of cutaneous B-cell lymphoma. Br J Dermatol 136:743-746.

Davis RL, Weintraub H, and Lassar AB (1987). Expression of a single transfected cDNA converts fibroblasts to myoblasts. Cell 51:987-1000.

DeRisi J, Penland L, Brown PO, Bittner ML, Meltzer PS, Ray $\mathrm{M}$, and Chen $\mathrm{Y}$ (1996). Use of a cDNA microarray to analyze gene expression patterns in human cancer. Nat Genet 14: 457-460.

Diatchenko L, Lau Y-F, Campbell AP, Chenchik A, Moqadam F, Huang B, Lukyanov S, Lukyanov K, Gurskaya N, Sverdlov ED, and Siebert PD (1996). Suppression subtractive hybridization: A method for generating differentially regulated or tissue-specific cDNA probes and libraries. Proc Natl Acad Sci USA 93:6025-6030.

Duguid JR, Rohwer RG, and Seed B (1988). Isolation of cDNAs of scrapie-modulated RNAs by subtractive hybridization of a cDNA library. Proc Natl Acad Sci USA 85:57385742.

Emmert-Buck MR, Bonner RF, Smith PD, Chuaqui RF, Zhuang Z, Goldstein SR, Weiss RA, and Liotta LA (1996). Laser capture microdissection. Science 274:998-1001.

Emmert-Buck MR, Gillespie JW, Paweletz CP, Ornstein DK, Basrur V, Appella E, Wang QH, Huang J, Hu N, Taylor P, and Petricoin EF3 (2000). An approach to proteomic analysis of human tumors. Mol Carcinog 27:158-165.

Fend F, Emmert-Buck MR, Chuaqui RF, Cole K, Lee J, Liotta LA, and Raffeld M (1999). Immuno-LCM: Laser capture microdissection of immunostained frozen sections for mRNA analysis. Am J Pathol 154:61-66.

Fernandes-Alnemri TF, Armstrong RC, Krebs J, Srinivasula SM, Wang L, Bullrich F, Fritz LC, Trapani JA, Tomaselli KJ, Litwack G, and Alnemri ES (1996). In vitro activation of CPP32 and Mch3 by Mch4, a novel human apoptotic cysteine protease containing two FADD-like domains. Proc Natl Acad Sci USA 93:7464-7469.

Goldsworthy SM, Stockton PS, Trempus CS, Foley JF, and Maronpot RR (1999). Effects of fixation on RNA extraction and amplification from laser capture microdissected tissue. Mol Carcinog 25:86-91.

Helin K, Lees JA, Vidal M, Dyson NJ, Harlow E, and Fattaey A (1992). A cDNA encoding a pRB-binding protein with properties of the transcription factor E2F. Cell 70:337-350.

Heller RA, Chai A, Shalon D, Bedilion T, Woolley DE, and Schena M (1997). Discovery and analysis of inflammatory disease-related genes using cDNA microarrays. Proc Natl Acad Sci USA 94:2150-2155.

lyer VR, Eisen MB, Ross DT, Schuler G, Moore T, Lee JCF, Trent JM, Staudt LM, Hudson J, Boguski MS, Lashkari D, Shalon D, Botstein D, and Brown PO (1999). The transcriptional program in the response of human fibroblasts to serum. Science 283:83-87.

Johnston PG, O’Brien MJ, Dervan PA, and Carney DN (1989). Immunhistochemical analysis of cell kinetic parameters in colonic adenocarcinomas, adenomas, and normal mucosa. Hum Pathol 20:696-700.

Jung B, Vogt T, Mathieu-Daude F, Welsh J, McClelland M, Trenkle T, Weitzel C, and Kullmann F (1998). Estrogenresponsive RING finger mRNA induction in gastrointestinal carcinoma cells following bile acid treatment. Carcinogenesis 19:1901-1906.

Leppä S, Saffrich R, Ansorge W, and Bohmann D (1998). Differential regulation of C-Jun by ERK and JNK during PC12 cell differentiation. EMBO J 17:4404-4413.

Luo L, Salunga RC, Guo H, Bittner A, Joy KC, Galindo JE, Xiao H, Rogers KE, Wan JS, Jackson MR, and Erlander MG (1999). Gene expression profiles of laser-captured adjacent neuronal subtypes. Nat Med 1:117-122.

Masutani C, Sugasawa K, Yanagisawa J, Sonoyama T, Ui M, Enomoto T, Takio K, Tanaka K, Spek PV, Bootsma D, Hoeijmakers $\mathrm{JH}$, and Hanaoka $\mathrm{F}$ (1994). Purification and cloning of a nucleotide excision repair complex involving the xeroderma pigmentosum group $\mathrm{C}$ protein and a human homologue of yeast RAD23. EMBO J 13:1831-1843.

McClelland M, Chada K, Welsh J, and Ralph D (1993). Arbitrary primed PCR fingerprinting of RNA applied to mapping differentially expressed genes. In: Pena SD, Charkraborty R, Epplen JT, and Jeffereys AJ, editors. DNA fingerprinting: State of the science. Basel: Birkhauser Verlag, 103-116.

McClelland M, Mathieu-Daude F, and Welsh J (1995). RNA fingerprinting and differential display using arbitrarily primed PCR. Trends Genet 11:242-245.

Nagasawa $\mathrm{Y}$, Takenaka M, Matsuoka Y, Imai E, and Hori M (2000). Quantitation of mRNA expression in glomeruli using laser-manipulated microdissection and laser pressure catapulting. Kidney Int 57:717-723. 
Ng PW, Porter AG, and Janicke RU (1999). Molecular cloning and characterization of two novel pro-apoptotic isoforms of caspase-10. J Biol Chem 274:10301-10308.

Oh JJ, Grosshans DR, Wong SG, and Slamon DJ (1999). Identification of differentially expressed genes associated with HER-2/neu overexpression in human breast cancer cells. Nucleic Acids Res 27:4008-4017.

Pandey S and Wang E (1995). Cells en route to apoptosis are characterized by the upregulation of c-fos, c-myc, c-jun, cdc2, and RB phosphorylation, resembling events of early cell-cycle traverse. J Cell Biol 58:135-150.

Potten CS and Allen TD (1977). Ultrastructure of cell loss in intestinal mucosa. J Ultrastruct Res 60:272-277.

Potten CS, Wilson JW, and Booth C (1997). Regulation and significance of apoptosis in the stem cells of the gastrointestinal epithelium. Stem Cells 15:82-93.

Ralph D, Welsh J, and McClelland M (1993). RNA fingerprinting using arbitrarily primed PCR identifies differentially regulated RNAs in mink lung (Mv1Lu) cells growth arrested by transforming growth factor beta 1. Proc Natl Acad Sci USA 90:10710-10714.

Schena M, Shalon D, Davis RW, and Brown PO (1995). Use of a cDNA microarray to analyze gene expression patterns in human cancer. Science 270:467-470.

Schutze K and Lahr G (1998). Identification of expressed genes by laser-mediated manipulation of single cells. Nat Biotechnol 16:737-742.

Sehgal A, Boynton AL, Young RF, Vermeulen SS, Yonemura KS, Kohler EP, and Aldape HC (1998). Application of the differential hybridization of Atlas Human Expression Arrays technique in the identification of differentially expressed genes in human glioblastoma multiforme tumor tissue. J Surg Oncol 67:234-241.
Sgroi DC, Teng S, Robinson G, LeVangie R, Hudson JR, and Elkahloun AG (1999). In vivo gene expression profile analysis of human breast cancer progression. Cancer Res 59:56565661.

Simone NL, Bonner RF, Gillespie JW, Emmert-Buck MR, and Liotta LA (1998). Laser-capture microdissection: Opening the microscopic frontier to molecular analysis. Trends Genet 14:272-276.

Suarez-Quian CA, Goldstein S, Pohida T, Smith PD, Peterson JI, Wellner E, Ghany M, and Bonner RF (1999). Laser capture microdissection of single cells from complex tissue. Biotechniques 26:328-335

Tam AS, Foley JF, Devereux TR, Maronpot RR, and Massey TE (1999). High frequency and heterogeneous distribution of p53 mutations in aflatoxin B1-induced mouse lung tumors. Cancer Res 59:3634-3640.

Trenkle T, Welsh J, Jung B, Mathieu-Daude F, and McClelland $M$ (1998). Non-stoichiometric reduced complexity probes for cDNA arrays. Nucleic Acids Res 26:3883-3891.

Usui H, Ichikawa T, Miyazaki Y, Nagai S, and Kumanishi T (1996). Isolation of cDNA clones of the rat mRNAs expressed preferentially in the prenatal stages of brain development. Brain Res Dev Brain Res 97:185-193.

Velculescu VE, Zhang L, Vogelstein B, and Kinzler KW (1995). Serial analysis of gene expression. Science 270:484-487.

Welsh J, Chada K, Dalal SS, Cheng R, Ralph D, and McClelland $M$ (1992). Arbitrarily primed PCR fingerprinting of RNA. Nucleic Acids Res 20:4965-4970.

Welsh J and McClelland M (1990). Fingerprinting genomes using PCR with arbitrary primers. Nucleic Acids Res 18: 7213-7218. 